\title{
EDITORIAL
}

\section{Peripheral lung remodelling in asthma and chronic obstructive pulmonary disease}

\author{
J. Hogg
}

In this issue of the European Respiratory Journal, VIGNOLA et al. [1] report an association between high-resolution computed tomography (HRCT) scan abnormalities of the conducting airways and an analysis of markers of the tissue remodelling process. They demonstrate an association between the level of HRCT abnormality in the airways and increased levels of active elastase with overproduction of tissue-inhibitor metalloproteinase-1 over metalloproteinase-9 in the sputum. The study design is cross-sectional in nature and based on small numbers of patients collected into three groups, according to whether they had newly diagnosed and untreated asthma, treated asthma or chronic obstructive pulmonary disease (COPD). The design does not include a control group with normal lung function and lacks longitudinal data collection to ensure that the sputum markers and HRCT abnormalities change in the expected directions with disease progression. After the first reading, the notion that editorial writers have been described as "the sort of people who come down from the hills after the battle is over to shoot the wounded" bubbled up in my thoughts. However, the temptation to take this approach passed with more careful evaluation of their manuscript.

Airflow limitation during forced expiration is a defining feature of both asthma, where it is reversible, and COPD, where an irreversible component remains after bronchodilator therapy. The emphysema phenotype of COPD destroys lung tissue beyond the terminal bronchioles and reduces the recoil force required to drive air out of the lung [2,3], whereas the airway-obstructive phenotype is produced by remodelling of the tissue in the walls of the smaller bronchi and bronchioles $<2 \mathrm{~mm}$ in diameter in the adult lung [4]. The question is: how can sputum collected at the mouth and HRCT images that encompass lesions produced by both phenotypes of the remodelling process contribute to our understanding of such a complex process?

The Edinburgh group was the first to use computed tomography $(\mathrm{CT})$ to diagnose emphysema in living patients with COPD [5], and improvements in this area of technology currently allow a fairly accurate assessment of the extent and severity of emphysema present in individuals with COPD [6-9]. Therefore, patients with COPD without radiological evidence of emphysema might exclusively have the small airway-obstructive phenotype of airflow limitation. Unfortunately, HRCT is not suited to the direct assessment of the site of obstruction in the small conducting airways because the walls of these airways provide too diminutive a target [10]. However, a Japanese study has shown that patients with COPD can be separated into emphysematous, airwayobstructive and mixed phenotypes, using estimates of CT lung density to determine the severity of emphysema and the

Correspondence: J. Hogg, iCAPTURE Centre for Cardiovascular and Pulmonary Research, 166-1081 Burrard St., Vancouver, BC V6Z 1Y6, Canada. Fax: 1 6048068351. E-mail: jhogg@mrl.ubc.ca thickened right apical segmental bronchus as a marker of the airway obstruction [11]. This suggests that changes in the HRCT estimates of larger airways reflect the remodelling process responsible for the fixed obstruction in much smaller airways, and the HRCT findings reported by VIGNOLA et al. [1] are consistent with this hypothesis, in that they correlate with the decline in forced expiratory volume in one second.

Sputum is a complex mixture of products from the lower airways that contains contributions from many levels in the tracheobronchial tree. The mucus is produced both by epithelial glands located in the submucosa of the larger bronchi and a population of mucus-producing cells that line both large and small conducting airways. The cellular content, solute and liquid that make up the bulk of the sputum come from many levels in the lower airways, including the alveolar surface. The analysis of sputum content has been standardised and validated by PIZZICHINI et al. [12], and is now used by many laboratories to investigate the inflammatory response in the lower airways. If the observations reported here by VIGNOLA et al. [1] reflect remodelling at the site of obstruction in the peripheral lung, it may be because, like the HRCT findings, the process responsible for the airway narrowing is more extensively present in the lower respiratory tract than just at the site of obstruction.

In summary, the combination of high-resolution computed tomography and sputum analysis appears to provide an indirect method for investigating an area of the lung that has been difficult to access. If the results of VIGNOLA et al. [1] can be repeated and shown to change in an appropriate manner with disease progression, this combination of techniques could yield important new information about the immune/ inflammatory/repair process thought to responsible for limiting expiratory flow. Indeed, if the substance of this report can be confirmed and extended to explore the mechanisms of both the small airway-obstructive and emphysematous phenotypes of peripheral lung remodelling, it could represent a milestone in the investigation of the site of airflow limitation in obstructive lung disease.

\section{References}

1. Vignola AM, Paganin F, Capieu L, et al. Airway remodelling assessed by sputum and high-resolution computed tomography in asthma and COPD. Eur Respir $J$ 2004; 24: 910917.

2. Global Initiative for Chronic Obstructive Lung Disease (GOLD). Global strategy for the diagnosis, management, and prevention of chronic obstructive pulmonary disease. NHLBI/WHO Workshop Report (NIH Publication 2701), April 2001. www.goldcopd.com. Date last accessed: October 12004.

3. Mead J, Turner JM, Macklem PT, Little J. Significance of 
the relationship between lung recoil and maximum expiratory flow. J Appl Physiol 1967; 22: 951-958.

4. Hogg J, Chu F, Utokaparch S, et al. The nature of small airway obstruction in chronic obstructive lung disease. $N$ Engl $J$ Med 2004; 350: 2645-2653.

5. Gould GA, MacNee W, McLean A, et al. CT measurements of lung density in life can quantitate distal airspace enlargement: an essential defining feature of human emphysema. Am Rev Respir Dis 1988; 137: 380-392.

6. Muller NL, Staples CA, Miller RR, Abboud RT. "Density mask". An objective method to quantitate emphysema using computed tomography. Chest 1988; 94: 782-787.

7. Gevenois PA, de Maertelaer V, De Vuyst P, Zanen J, Yernault JC. Comparison of computed density and macroscopic morphometry in pulmonary emphysema. Am J Respir Crit Care Med 1995; 152: 653-657.

8. Gevenois PA, De Vuyst P, de Maertelaer V, et al. Comparison of computed density and microscopic morphometry in pulmonary emphysema. Am J Respir Crit Care Med 1996; 154: 187-192.

9. Coxson HO, Rogers RM, Whittall KP, et al. A quantification of the lung surface area in emphysema using computed tomography. Am J Respir Crit Care Med 1999; 159: 851-856.

10. Nakano Y, Whittall KP, Kalloger SE, Coxson HO, Pare PD Development and validation of human airway analysis algorithm using multidetector row CT. Proceedings of SPIE 2002; 4683: 460-469.

11. Nakano Y, Muro S, Sakai H, et al. Computed tomographic measurements of airway dimensions and emphysema in smokers. Correlation with lung function. Am J Respir Crit Care Med 2000; 162: 1102-1108.

12. Pizzichini E, Pizzichini MM, Efthimiadis A, et al. Indices of airway inflammation in induced sputum: reproducibility and validity of cell and fluid-phase measurements. Am J Respir Crit Care Med 1996; 154: 308-317. 